\title{
A Checklist For A Successful PD Student Project
}

Simonsen, Jesper; Z. Malik, Aisha; From, Gustav; F. Parslov, Marie; T. Sørensen, Lars

Published in:

Proceedings of the 16th biennial Conference on Participatory Design

DOI:

$10.1145 / 3384772.3385132$

Publication date:

2020

Document Version

Early version, also known as pre-print

Citation for published version (APA):

Simonsen, J., Z. Malik, A., From, G., F. Parslov, M., \& T. Sørensen, L. (2020). A Checklist For A Successful PD Student Project. In C. Del Gaudio, L. Parra, S. Agid, G. Poderi, D. Duque, L. Villezcas, A. Botero, F. C. Londoño, \& P. Escandón (Eds.), Proceedings of the 16th biennial Conference on Participatory Design: PDC'2020, June 15-19, Manizales, Colombia: Participation(s) otherwise (Vol. II, pp. 119-123). Association for Computing Machinery. https://doi.org/10.1145/3384772.3385132

\section{General rights}

Copyright and moral rights for the publications made accessible in the public portal are retained by the authors and/or other copyright owners and it is a condition of accessing publications that users recognise and abide by the legal requirements associated with these rights.

- Users may download and print one copy of any publication from the public portal for the purpose of private study or research.

- You may not further distribute the material or use it for any profit-making activity or commercial gain.

- You may freely distribute the URL identifying the publication in the public portal.

Take down policy

If you believe that this document breaches copyright please contact rucforsk@kb.dk providing details, and we will remove access to the work immediately and investigate your claim. 


\title{
A Checklist For A Successful PD Student Project
}

\section{Jesper Simonsen}

Department of People and Technology, Roskilde University, Roskilde, Denmark, simonsen@ruc.dk

\author{
Aisha Z. Malik \\ Digestive Disease Center, Bispebjerg Hospital, Copenhagen, Denmark, \\ aishimalik@gmail.com

\section{Gustav From} \\ Digestive Disease Center, Bispebjerg Hospital, Copenhagen, Denmark, \\ gustav.from@regionh.dk
}

\section{Marie F. Parslov}

Digestive Disease Center, Bispebjerg Hospital, Copenhagen, Denmark, marieparslov@gmail.com

\section{Lars T. Sørensen}

Digestive Disease Center, Bispebjerg Hospital, Copenhagen, Denmark, lars.tue.soerensen@regionh.dk

\section{ABSTRACT}

We identify and exemplify a general checklist of eight important conditions required for a successful Participatory Design (PD) student project with external partners. We address projects aiming to embrace both analysis, design, implementation, and evaluation in complex real-life settings. The checklist is intended to support students, academic institutions, and private/public collaborative partners in planning, initiating, conducting and realizing larger student-driven PD projects.

\section{CCS CONCEPTS}

- Human-centered computing Interaction design Interaction design process and methods $\sim$ Participatory design • Social and professional topics Professional topics Computing education • Applied computing Education Collaborative learning

\section{KEYWORDS}

Participatory design, Student project, Checklist for projects, Conditions for success, Pilot implementation, Real-life settings, External partners, Student-driven project

\section{Introduction}

Many university programs may include relatively large Participatory Design (PD) student projects, typically as part of a bachelor, master or $\mathrm{PhD}$ thesis. These projects are typically initiated by the student with a desire for close collaboration with external partners and with a wish to help these partners make desired changes. The initial plans for the empirical PD project often include the ambition of conducting one or several iterations striving for real-life change. 
Usually the initial plans are never fully realized because interacting with real-life change is very unpredictable, complex, and entails a high dependency on the involvement and deliveries from the external partners that the student has very little or no power to influence.

We present and review a PD student project that, within only five months, successfully managed to establish a close collaboration with clinicians at a hospital in Denmark, complete analysis, design, and implementation of IT-supported desired change (using the Epic healthcare platform, epic.com), and evaluate the effects of the change. The project hereby resembles the iteration recommended for healthcare PD projects [1] and the iterations done in several recent PD PhD-projects [e.g. 2-5].

Our literature review1 reveal PDC workshops on teaching PD [7-10], and a recent book release on how PD contribute to the learning sciences [11]. However, "the existing literature is noticeably lacking in publications concerning teaching PD" [12, p. 1]. PD has been discussed as part of the curriculum of university programs [13; 14]; as a key subject in university courses [15; 16]; including courses engaging students in PD processes though live projects $[12 ; 17]$. Other papers include use of PD-techniques in teaching [18; 19]; using collaboration tools to support educational group work [20]; a students' reflections on a PD project [21]; and teaching PD for secondary school students [22]. This paper contributes to the research on learning PD through real-live projects [e.g. 12; 17]. We elicit eight general conditions required for larger PD student projects to embrace both design, implementation, evaluation, and collaboration with external partners in complex real-life settings.

In the following we introduce the hospital setting, starting point, main activities, and evidence of the high impact as a result of a PD master's thesis project2. We then present our analysis 3 identifying and exemplifying eight conditions that enabled the success of the project. We elaborate and describe these eight conditions as a general checklist for student projects with ambitions of conducting a full PD-iteration implementing changes to a real-world setting.

\section{Setting, Material and Baseline Flow of Work}

The project took place at the Digestive Disease Center, named in Danish "Abdominalcenter K" (AK), a hospital department comprising the specialities surgery and gastroenterologyhepatology. Within the department, there are outpatient clinics, patient wards, and operationand endoscopy units. AK is situated at Bispebjerg Hospital, a teaching hospital in the Capital Region of Denmark, providing surgical care for 465.000 inhabitants in the city of Copenhagen and for some diseases the Faroe Islands and Bornholm. The staff of AK is familiar with the process of doing projects, and AK includes a research unit for health informatics, facilitating the inclusion of master and $\mathrm{PhD}$ thesis projects into the clinical field of work. The center received 4.104 referrals (2018), mainly from general practitioners. Among these 1.320 were referred for the care of inguinal hernia (DK40.0, DK40.9), umbilical hernias (DK42.0, DK42.9)), and gallbladder stones (DK80.2)4. These referrals, including the clinical visitation, comprised the material for this study.

At baseline, three medical secretaries in an organized workflow and with functionalities in Epic, managed the referrals' administrative tasks, coordination, and communication. Incoming

1 Review conducted by the PRISMA approach [] ] including a search on the complete archive of Participatory Design Conference Proceedings (pdcproceedings.org) with the search string: "Participatory design" AND (Teaching OR supervis* OR student* OR "thesis project*").

2 A master's thesis concludes a 5-year university master program and must, in Denmark [23], be of 30 ECTS [24], equivalent to one full semester's work and approximately 825 hours of student work. The PD student project in this paper is from the second semester of 2018 [25].

3 Analysis made by the authors, i.e. the university professor supervising the student, the master's thesis student, and three clinicians from the hospital that participated in the project: the quality responsible chief physician, a nurse specialized in IT, and the executive chief physician.

4 Codes are referring to the Danish version of WHO's ICD-10 classification of diseases (who.int/classifications/icd/icdonlineversions/en). 
referrals were registered and forwarded to three designated physicians. They then assessed the cases on referring physicians' information and on available previous notes and test results documented in Epic. If accepted, subsequent examinations, appointments and treatment were planned. Judgements and plans were forwarded to the secretaries, who made the registration work, the booking of tests and appointments, and informed patients, mainly by digital mail.

The present workflow posed several challenges to AK: (1) Plans were not standardized and could be ambiguous imposing secretaries to search physicians for clarification. (2) Referrals changed hands from secretaries to physicians and back, which implied secretaries had to deal with the same referral twice, often several days apart, causing both errors triggered by oversights and a rise in secretaries' workload. (3) Physicians' flow of assessing referrals was irregular as they were busy in the operating theatre, doing ward rounds, etc. Hence, referrals could await assessment for days and be assessed in large batches disorganizing secretaries' work. (4) Turnover time for referrals was one of several obstacles for compliance to the timelimits for the start of patients' investigation and treatment given by the Danish parliament.

\section{The Student Project}

The establishment of the student project was facilitated by AK having experience and motivation of including student projects. The student was familiar with clinical work and Epic from her background being part-time employed for 1.5 years in a student job as Epic supporter for the hospital. The student was granted daily open access to AK, a nurse specialized in IT was allocated as resource for establishing project activities (meetings, observations, interviews, workshops, etc.), and the student and the project was highly recognized by management including the executive chief physician, the executive medical secretary, and the quality responsible chief physician. Management participation was highly important as the research question of the master's thesis developed into "How can PD and effects-driven IT-development improve the visitation process through a re-allocation of tasks from physicians to medical secretaries?" [25, p. 12]. While a re-allocation of the visitation had potentials for meeting the workflow challenges described above, it is also sensitive, especially to the medical secretaries who are to undertake this task. This gave the project a crucial focus on PD.

The student project was grounded in PD literature, with the analysis and design part based on the MUST PD-method [26; 27], and the implementation formed as a pilot implementation [28], that is, a field trial implementation of the change for a limited period of time to evaluate real-use experience. The project and its evaluation were effects-driven [29; 30], specifying the wished-for effects and measuring these effects before as well as after the implementation. Additional theory supported sensemaking [31], genuine PD [26; 32; 33] and change management [34].

Activities during analysis and design included one week of observations of the medical secretaries and one day observing a physician handling the visitation. Observations were supported by quantitative data of the process extracted from Epic. Observations and meetings with the medical secretaries identified a number of challenges in their work processes and extensive use of Epic. They also expressed their worries facing a project of re-allocating (i.e. adding to their field of work) a task usually done by the physicians. This legitimate concern and the conditions for the medical secretaries' current work practice was brought to management meetings by the student. The student held workshops with the medical secretaries where they designed a visitation process to be managed solely by the medical secretary (depicted in figure 1, left side). They also outlined the challenges experienced by the medical secretaries along with wished-for effects to meet these (depicted in figure 1, right side). Through a close collaboration with management, the nurse specialist, and the secretaries, a pilot implementation was co-designed including and evaluating: (1) The overall wished-for effect of reduced patient response time due to re-allocating the visitation process; (2) whether the re- 
allocation would in fact reduce the work of the medical secretaries as an effect of completing the visitation in one step by one medical secretary (as opposed to being exchanged between a physician and several medical secretaries); (3) how the medical secretary, if needed, immediately could hand over complex visitation cases to the executive chief physician; and finally, (4) how to remedy other related challenges experienced by the medical secretaries.

The pilot implementation was organized and conducted by the student, the nurse specialist, and management. They made a detailed guideline including a decision framework for which type of visitations should be handled by the medical secretaries or the physicians. The student was allocated as Epic-supporter when the pilot implementation was initiated. An unanticipated and emergent change [29; 35] related to checking patient medication status was quickly addressed, and the visitation process and guideline was re-considered and re-configured accordingly.

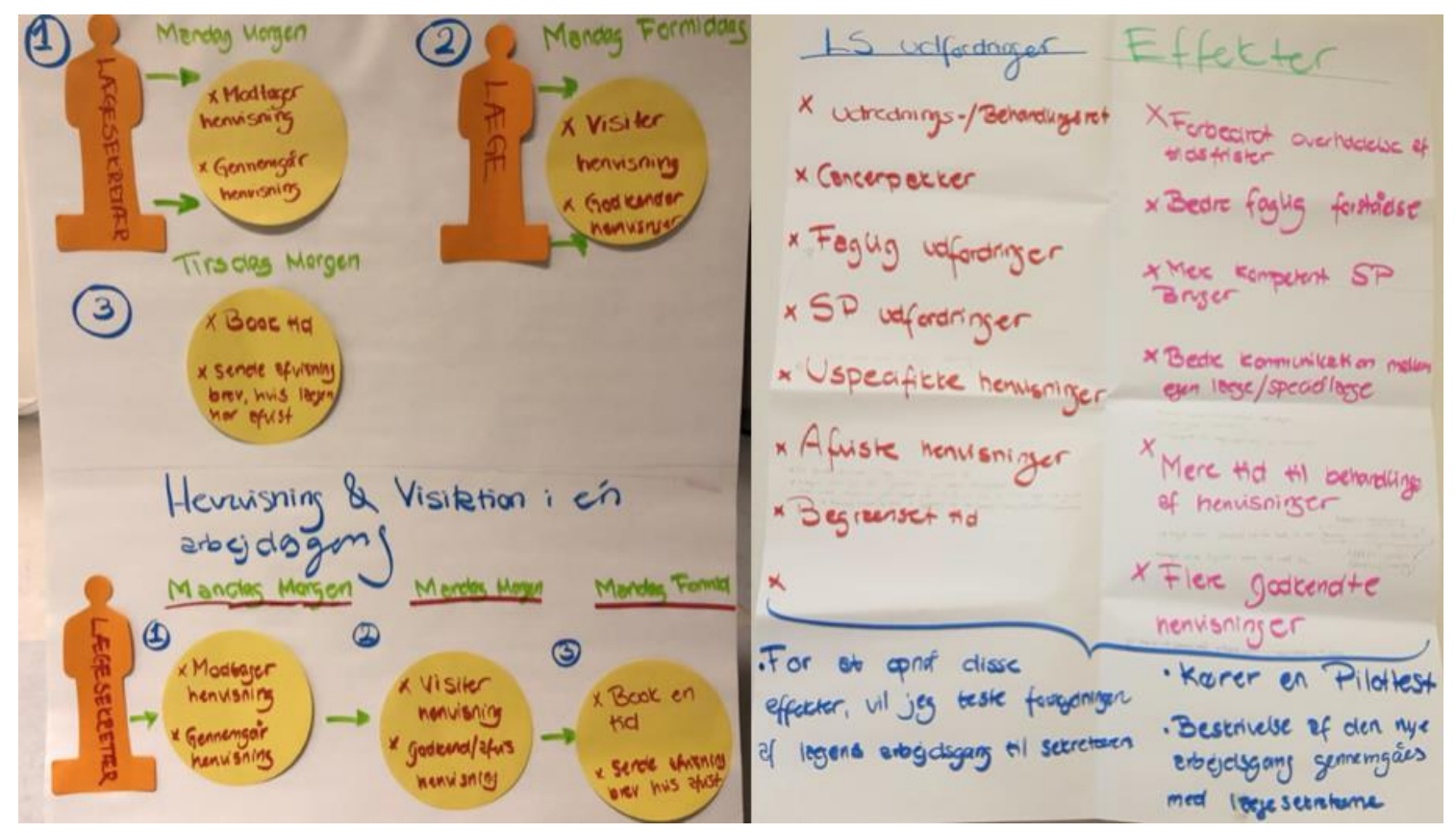

Figure 1. Models of an 'as-is' and an envisioned 'to-be' process (left). Challenges and alleviating effects (right).

The evaluation comprised effects assessments [29;30] conducted by the student three weeks into the pilot implementation, including observations and an analysis based on data from Epic. The Epic data comprised 143 visitations from a three months period prior to the pilot implementation and 53 visitations from the three weeks period after the pilot implementation. These results might provide statistical evidence of the effects. The student, due to time constraints, made a random check of 12 cases and measured another two from direct observations: This indicated and convincingly illustrated the effects of a visitation process time dropping from up to a week and down to seven minutes. The evaluation of the project demonstrated a work-related win-win situation for both medical secretaries and physicians. The impressive impact of reducing patient response time from days to minutes led to a decision of permanently continuing the pilot implementation and to plans for scaling the project to more complicated cancer referral programs.

\section{A Checklist of Eight General Conditions}

The conditions for the student project were, overall, favored by a teaching hospital setting and management motivated and experienced in embracing student projects, and a student with 
relevant contextual and technical prerequisites. Our review of the project identifies eight general conditions facilitating the project. No single condition explains the success. Rather, multiple conditions interact and reinforce each other, a point also given in a recent review of 'factors that influence the implementation of e-health' [36].

First, the project shortly became clearly focused, defined and scoped. The chosen clinical visitation process was delimited to three relatively simple diagnoses. This part of the referral workflow is handled by clinicians within AK, i.e. a process that does not involve or entangle inter-departmental coordination known to increase the complexity of a change project [37]. The aim of the project as a field trial of re-allocating the visitation task also comprise a focus and 'business case' that is easy to introduce and communicate to the participating clinicians. The visitation process could be illustrated in models of an 'as-is' and an envisioned 'to-be' process (see Figure 1) without special formalisms, but as simple drawings of the freehand drawing and collage type [26]. These models played an important role as a common reference point for the participants. Finally, the limited project scope eased a pilot implementation: Scoping is known to be a serious challenge for pilot implementations [28]. Defining, scoping, and focusing a PD student project in its early phase require support and engagement from both the students' supervisor and the external partner. A successful focus may typically include a specific 'as-is' business process that can be illustrated in a relatively simple model.

Second, the project was of high relevance to the workplace. The physicians were very interested in allocating the visitation task to the secretary: The majority of these tasks are uncomplicated from a clinical perspective but administratively complex requiring several enquiries in Epic - a system that most physicians find very cumbersome [38]. The visitation process is also subjected to the Danish national cancer control plan including deadlines for fasttrack fixed "packages" for diagnosis and treatment [39]. While the required deadlines were not critical for the chosen diagnoses, a successful project would inspire scaling similar changes to more complicated cancer treatments, which have tighter deadlines, difficult for AK to meet, and which have a political vigilance. A successful pilot implementation would therefor provide attractive opportunities for both physicians and management at AK, i.e. the project's most powerful stakeholders. The external partner's engagement and commitment might be closely correlated to the projects' relevance for the workplace. Contrary, lack of an evident need is known as an impeding condition [40].

Third, the project received active managerial commitment. A project that involves real-life implementation and changes for the users from the workplace requires acceptance by management. In our case the AK's executive chief physician went whole-hearted and dedicated into the project. This was important not only to support the student but because the intended change involved a sensitive and potentially conflictual re-allocation of tasks to the medical secretaries: They could fear both task overload and allocation of a task outside their area of responsibility that they could question if they had sufficient qualifications for. Management played an important role by guaranteeing promptly to take over any visitation case that the medical secretary did not feel confident doing. Lack of management commitment is a wellknown risk factor [41]. PD projects engaging with potentially sensitive and conflicting changes should require up-front management engagement and support. It is the commitment from the department management rather than top-management that is known to be vital [40].

Fourth, concerned users became engaged in genuine participatory design. An important challenge from a PD perspective was the concern from the medical secretaries being asked to take over a task from the area of responsibility of the physicians. Positioned in the low end of the hospital hierarchy their concern included not only the obvious risk of task overload but, more importantly, fear of not being sufficiently qualified. This calls for 'genuine participation' with open-minded contact and authentic meetings that enable such worries can be voiced and taken seriously [33; 42]. The student succeeded to establish genuine participation with the 
medical secretaries by allowing them to (1) respect their own interests, (2) being open to how they felt about the re-allocation, and their reflections on their own opinions about this, and, (3) willingly make them contribute to the achievement of the goals of the project. These three characteristics of genuine participation used in the project, were introduced in [32, p. 5], elaborated into a conceptual framework for genuine participation in [33], and supporting PD techniques are outlined in [42]. This approach to genuine participation transformed medical secretaries' understandable skeptical attitude into a shared and agreed-upon pilot implementation with a "win-win" prospect for medical secretaries as well as physicians.

Fifth, adequate workplace resources (participation and time) were allocated. The project received priority within AK and was not challenged by other competing activities or priorities. Resources were allocated when needed within the required timeframe of the project. This included management and staff participation in planned PD activities and instant support when needed, for example from management approaching the medical secretaries as described above. Also, the nurse specialist was delegated to take charge of all project activities at AK such as supporting the student in making arrangements with other participants (e.g., scheduling and allocating medical secretaries for PD activities), drafting clinical guidelines for the new visitation process, informing and preparing the pilot implementation (a comprehensive task in a 3-shift 24/7 environment), etc. Resource allocation may ideally be agreed upon and stated as part of a project establishment charter [26].

Sixth, the project participants comprised the needed competences. Project teams configuring information systems and work practices for each other requires a pool of local competencies including understanding of practice and technology, project management, competencies in preparing, making, and assessing change, and personal traits [43]. The student had specific technical and organizational qualifications due to a student job as Epic supporter for the hospital. The student's project management skills were shaped by a master program where $50 \%$ of the curriculum is independent project work [44]. Detailed knowledge of current work practices was acquired through observations and PD activities with clinicians. The student's competencies were supported by the delegated nurse specialist and management, among others with preparing, conducting, and managing the pilot implementation and changes to work procedures. All required competencies, skills and knowledge are elaborated in [43], and some of these might deliberately be acquired as part of the aim and learning activity of a pilot implementation [28].

Seventh, technical and organizational change could be accomplished solely by the project participants. The visitation process was chosen, among others, because it exclusively involved clinicians within AK. Technical and organizational implications of the pilot implementation turned out also to be accomplishable by the project participants themselves. This not always the case for pilot implementations and it is difficult or impossible to predict from the project start [28]. The needed technical changes were few, and could be configured in Epic by the student without further authorization or involvement by the central IT-organization. The organizational change setting up the new re-allocation of tasks could also be accomplished by the participants from AK independently from other external organizational units. An important condition for a successful local pilot implementation is the presence of the competencies required for the technical and organizational change [28; 43].

Eighth, assessment of the effects and impact was possible within a short timeframe. Making effects assessments of a newly established IT-supported work process often involve considerable resources and relatively long time periods [e.g. 45; 46], and sometimes the desired effects are not realized at all [47]. The effects measurements in this case were possible to do, by the student, using Epic's report generator where timestamps from the patient referral and the approval of the visitation were compared to calculate the time of the visitation process. A high volume of patient visitations enabled sufficient evaluation data three weeks into the pilot 
implementation. If the technology does not support effects assessment an alternative dedicated evaluation infrastructure should be considered as suggested by [5].

\section{Conclusion}

A PD student project with the ambition of including a full iteration aiming for real-life change is a tremendous learning opportunity - also when the goal is only partly achieved. The project needs to ensure that students achieve their learning goals, while delivering practical benefits for the external partners, who place their trust in the students and the university program. We offer a general and exemplified checklist of eight essential conditions for students, their supervisors, and collaborative partners. The checklist aims at helping them initiate, conduct, and realize such PD projects. We hope this checklist can foster a collaborative culture of reflection and thought concerning the conditions needed to achieve the intended synergy to ensure successful PD student projects.

\section{REFERENCES}

[1] Clemensen, Jane, Rothmann, Mette J, Smith, Anthony C, Caffery, Liam J, and Danbjorg, Dorthe B 2017. Participatory design methods in telemedicine research. Journal of Telemedicine and Telecare. 23, 9, 780-785. DOI: https://doi.org/10.1177/1357633x16686747.

[2] Jensen, Charlotte Myhre. 2018. Tele-health for patients with hip fracture - a participatory design study exploring how to support self-care and empowerment. Ph.D.-thesis, Department of Orthopaedic Surgery and Traumatology, Odense University Hospital.

[3] Holm, Kristina Garne. 2017. Neonatal Tele-Homecare. Ph.D.-thesis, Department of Clinical Research, University of Southern Denmark.

[4] Nielsen, Charlotte, Agerskov, Hanne, Bistrup, Claus, and Clemensen, Jane 2019. User involvement in the development of a telehealth solution to improve the kidney transplantation process: A participatory design study. Health Informatics Journal. 146045821987618. DOI: https://doi.org/10.1177/1460458219876188.

[5] Brandrup, Morten. 2018. Designing an Evaluation Infrastructure for Effects-driven Healthcare IT Development. Ph.D.-thesis, Department of People and Technology, Roskilde University.

[6] Moher, David, Liberati, Alessandro, Tetzlaff, Jennifer, and Altman, Douglas G 2009. Preferred Reporting Items for Systematic Reviews and Meta-Analyses: The PRISMA Statement. PLoS Medicine. 6, 7, e1000097. DOI: https://doi.org/10.1371/journal.pmed.1000097.

[7] Winograd, Terry, Kautz, Karlheinz, Greenbaum, Joan, and Muller, Michael J. 1994. Teaching participatory design. Proceedings of the 3rd biennial Participatory Design Conference, PDC 1994, Chapel Hill, NC, USA, October 27-28 1994. Palo Alto, CA: CPSR. 73.

[8] Andersdotter, Gunnel, Eriksén, Sara, Bergqvist, Betty, and Dittrich, Yvonne 2000. Mixing Disciplines in Teaching Participatory Design Practices. Proceedings of the 6th biennial Participatory Design Conference, PDC 2000, New York, NY, USA, 28 November - 1 December 2000: Designing Digital Environments. Palo Alto, CA: CPSR. 219-220.

[9] Kensing, Finn, Keld Bødker, and Simonsen, Jesper 2004. Teaching Participatory Design. Proceedings of the eighth Participatory Design Conference 2004, PDC 2004, Artful Integration: Interweaving Media, Materials and Practices, July 27-31, 2004 Toronto, Canada.Palo Alto, CA: CPSR. 209-210.

[10] Andrews, Barbara, Bardzell, Shaowen, Clement, Andrew, D’Andrea, Vincenzo, Hakken, David, Poderi, Giacomo, Simonsen, Jesper, and Teli, Maurizio 2014. Teaching participatory design. Proceedings of the 13th biennial Participatory Design Conference, PDC 2014, Windhoek, Namibia, October 6-10, 2014: Reflecting Connectedness. New York, NY: ACM. 203-204. DOI: https://doi.org/10.1145/2662155.2662202.

[11] DiSalvo, Betsy, Yip, Jason, and DiSalvo, Elizabeth Bonsignore Carl 2017. Participatory design for learning: perspectives from practice and research. Routledge, Taylor \& Francis Group, New York. DOI: https://doi.org/10.4324/9781315630830.

[12] Christiansson, Jörn, Grönvall, Erik, and Yndigegn, Signe Louise 2018. Teaching participatory design using live projects: critical reflections and lessons learnt. Proceedings of the 15th Participatory Design Conference, August 20-24, 2018, Hasselt and Genk, Belgium: Participatory 
Design, Politics and Democracy, New York, NY: ACM. 8:1-8:11. DOI: https://doi.org/10.1145/3210586.3210597.

[13] Kautz, Karlheinz 1994. On Participatory Design and User Involvement as Topics in Computing Education: A Contribution to a Curriculum Debate. Proceedings of the 3rd biennial Participatory Design Conference, Chapel Hill, NC, USA, October 27-28 1994. Palo Alto, CA: CPSR. 67-72.

[14] Gelderblom, Helene. 2017 Co-designing an HCI curriculum with college students and teaching them about participatory design in the process. In Participatory design for learning : perspectives from practice and research, Betsy DiSalvo, Jason Yip, and Elizabeth Bonsignore Carl DiSalvo (eds.). Routledge, Taylor \& Francis Group, New York. 71-87. DOI: https://doi.org/10.4324/9781315630830.

[15] Hecht, K Maike and Maass, Susanne 2008. Teaching participatory design. Proceedings of the 10th biennial Anniversary Conference on Participatory Design, Bloomington, Indiana, USA, October 1-5, 2008: Experiences and Challenges,New York, NY: ACM. 166-169.

[16] D'Andrea, Vincenzo and Teli, Maurizio 2010. Teaching participatory design: a participatory approach. Proceedings of the 11th Biennial Participatory Design Conference, Sydney, Australia, November 29 - December 3, 2010: Participation $::$ the Challenge, New York, NY: ACM. 223226. DOI: https://doi.org/10.1145/1900441.1900486.

[17] Iversen, Morten Moth, Madsen, Jan Ernfred, and Vesterstrøm, Jakob Svaneborg 2000. Learning Participatory Design by Participatory Design. Proceedings of the 6th biennial Participatory Design Conference, New York, NY, USA, 28 November - 1 December 2000: Designing Digital Environments, Palo Alto, CA: CPSR. 287-290.

[18] Loi, Daria 2004. Document/Reflect/Create Cultural Probes in Teaching and Learning Environments. Proceedings of the 8th biennial Participatory Design Conference, Toronto, Canada, July 27-31, 2004: Interweaving Media, Materials and Practices, Volume 1, New York, New York, NY: ACM. 123-126.

[19] Törpel, Bettina 2006. The design game in participatory design and design education: chances, risks and side effects. Proceedings of the ninth biannual Participatory Design Conference, Trento, Italy, August 1-5, 2006: Expanding Boundaries in Design, New York, NY: ACM. 1, 7786.

[20] Graham, Mary, Phillips, Chantal, Lyons, Donna, and Clement, Andrew 1998. Building a Room of Our Own: The Cooperative Design of Web-based Group Project Support for an Educational Community. Proceedings of the 5th biennial Participatory Design Conference, Seattle, WA, USA, 12-14 November 1998: Broadening Participation, Palo Alto, CA: CPSR. 219-228.

[21] Stam, Donna and Boon, Boudewijn 2018. What you gain and what it takes: a student's reflection on a participatory design project. Proceedings of the 15th Participatory Design Conference, August 20-24, 2018, Hasselt and Genk, Belgium: Participatory Design, Politics and Democracy, New York, NY: ACM. Article 9, 4 pages. DOI: https://doi.org/10.1145/3210604.3210626.

[22] Lee, Yanki and Ho, Kwok Leung Denny 2010. 'Teaching the teachers' investigating new inclusive design experience to enable secondary school students to think creatively. Proceedings of the 11th biennial Participatory Design Conference, PDC 2010, Sydney, Australia, November 29 - December 3, 2010: Participation :: the Challenge. New York, NY: ACM. 203-206. DOI: https://doi.org/10.1145/1900441.1900479.

[23] Education, Danish Agency for Science and Higher. 2016. Act of Bachelor and Master Programs at the Universities (Act \#1328-15/11/2016). Ministry of Higher Education and Science, Copenhagen, Denmark.

[24] The European Commission. 2019. European Credit Transfer and Accumulation System (ECTS). Retrieved November 115, 2019 from https://ec.europa.eu/education/resources-andtools/european-credit-transfer-and-accumulation-system-ects_en.

[25] Malik, Aisha Zahoor. 2019. Optimering af visitationsopgaven [Improving the Visitation Task]. Master-thesis, Department of People and Technology, Roskilde University.

[26] Bødker, Keld, Kensing, Finn, and Simonsen, Jesper. 2004. Participatory IT Design. Designing for Business and Workplace Realities. MIT Press, Cambridge, Massachusetts.

[27] Bødker, Keld, Kensing, Finn, and Simonsen, Jesper. 2011 Participatory Design in Information Systems Development. In Reframing Humans in Information Systems Development, Hannakaisa Isomäki and Samuli Pekkola (eds.). Springer-Verlag London Limited. 115-134. DOI: https://doi.org/10.1007/978-1-84996-347-3_7. 
[28] Hertzum, Morten, Bansler, Jørgen P., Havn, Erling C., and Simonsen, Jesper 2012. Pilot Implementation: Learning from Field Tests in IS Development. Communications of the Association for Information Systems. 30, 1, 313-328. DOI: https://doi.org/10.17705/1CAIS.03020

[29] Hertzum, Morten and Simonsen, Jesper 2010. Effects-Driven IT Development: An Instrument for Supporting Sustained Participatory Design. Proceedings of the 11th Biennial Participatory Design Conference, Sydney, Australia, November 29 - December 3, 2010: Participation $\because:$ the Challenge,New York, NY: ACM. 61-70. DOI: https://doi.org/10.1145/1900441.1900451.

[30] Hertzum, Morten and Simonsen, Jesper 2011. Effects-Driven IT Development Specifying, Realizing, and Assessing Usage Effects. Scandinavian Journal of Information Systems. 23, 1, 126. DOI: https://doi.org/10.1145/1900441.1900451.

[31] Weick, Karl E. 1995. Sensemaking in Organizations. Sage Publications, Thousand Oaks, CA.

[32] Robertson, Toni and Simonsen, Jesper. 2013 Participatory Design: An Introduction. In Routledge International handbook of Participatory Design, Jesper Simonsen and Toni Robertson (eds.). Routledge, New York, NY.

[33] Østergaard, Kija Lin, Simonsen, Jesper, and Karasti, Helena 2018. Examining situated design practices: Nurses' transformations towards genuine participation. Design Studies. 59, 37-57. DOI: https://doi.org/10.1016/j.destud.2017.12.002.

[34] Northouse, Peter G. 2016. Leadership: Theory and practice. Sage Publications, Thousand Oaks, CA.

[35] Orlikowski, Wanda and Hofman, Debra 1997. An Improvisational Model for Change Management: The Case of Groupware Technologies. Sloan Management Review. 38, 2, 11-22.

[36] Ross, J, Stevenson, F, Lau, R, and Murray, E 2016. Factors that influence the implementation of e-health: a systematic review of systematic reviews (an update). Implement Science. 11, 1, 146. DOI: https://doi.org/10.1186/s13012-016-0510-7.

[37] Lassen, Jens Vejrup and Simonsen, Jesper. 2014 User-Driven Designs in Medical Informatics: Developing and Implementing Support for Inter-departmental Coordination of Hospital Work using Electronic Whiteboards. In Selected Papers of the Information Systems Research Seminar in Scandinavia, Issue Nr. 5, IRIS 37 -Designing Human Technologies. Paper 7, J. MolkaNielsen and J. Pries-Heje (eds.). Association for Information Systems Electronic Library (AISeL),

[38] Gawande, Atul 2018. Why doctors hate their computers. The New Yorker Annals of Medicine. 12, $1-31$.

[39] Storm, Hans Henrik, Kejs, AM, and Engholm, Gerda 2011. Improved survival of Danish cancer patients 2007-2009 compared with earlier periods. Danish Medical Bulletin. 58, 12, A4346.

[40] Hertzum, Morten and Simonsen, Jesper 2020. How Come Nothing Changed? Reflections on the Fasting-Time Project. Proceedings of the 30th Medical Informatics Europe conference (MIE 2020), 28th April-1st May, Geneva: Digital Personalized Health. Amsterdam, The Netherlands: IOS Press.

[41] Arnuphaptrairong, Tharwon 2011. Top ten lists of software project risks: Evidence from the literature survey. Proceedings of the International MultiConference of Engineers and Computer Scientists, IMECS, Hong Kong, March 16-18. Vol. I.

[42] Simonsen, Jesper and Jensen, Olav Storm 2016. Contact Quality in Participation: A "Sensethic" Perspective. Proceedings of the 14th Participatory Design Conference, August 15-19, 2016, Aarhus, Denmark: Participatory Design in an era of participation. 45-48. DOI: https://doi.org/10.1145/2948076.

[43] Hertzum, Morten and Simonsen, Jesper 2019. Configuring information systems and work practices for each other: What competences are needed locally. International Journal of HumanComputer Studies. 122, 242-255. DOI: https://doi.org/10.1016/j.ijhcs.2018.10.006.

[44] Andersen, Anders Siig and Heilesen, Simon B. 2015. The Roskilde Model: Problem-Oriented Learning and Project Work. Innovation and Change in Professional Education. Springer, Heidelberg, New York, London. DOI: https://doi.org/10.1007/978-3-319-09716-9.

[45] Hertzum, Morten and Simonsen, Jesper 2008. Positive effects of electronic patient records on three clinical activities. International Journal of Medical Informatics. 77, 12, 809-817. DOI: https://doi.org/https://doi.org/10.1016/j.ijmedinf.2008.03.006. 
[46] Hertzum, Morten and Simonsen, Jesper 2016. Effects of electronic emergency-department whiteboards on clinicians' time distribution and mental workload. Health Informatics Journal. 22, 1, 3-20. DOI: https://doi.org/10.1177/1460458214529678.

[47] Simonsen, Jesper, Karasti, Helena, and Hertzum, Morten 2020. Infrastructuring and Participatory Design: Exploring Infrastructural Inversion as Analytic, Empirical and Generative. Computer Supported Cooperative Work (CSCW), 29, 115-151. https://doi.org/10.1007/s10606-019-09365w. 